- Outlines the role of the general dental practitioner in the diagnosis of a tonsillolith in panoramic radiography.

- Emphasises the importance of the medical history in the final diagnosis.

- Explains the role of differential diagnosis of a tonsillolith and other diseases.

\title{
Tonsillolith - report of an unusual case
}

\author{
M. P. Caldas, ${ }^{1}$ E. G. Neves, ${ }^{2}$ F. R. Manzi, ${ }^{3}$ S. M. de Almeida, ${ }_{1}^{4}$ F. N. Bóscolo ${ }^{5}$ and F. Haiter-Neto ${ }^{6}$
}

\begin{abstract}
Tonsilloliths are rare concretions found in the tonsillar crypt. They are usually single and unilateral, but occasionally may be multiple or bilateral. This report describes a case of a 47-year-old woman whose radiography revealed one radiopaque image located in the right ramus of the mandible. The patient revealed a history of slight dysphagia, halitosis and swallowing pain with a foreign body sensation. Her medical history revealed a tonsillectomy when she was eight years old and the removal of the uvula because of sleep apnoea six years ago. Computer tomography showed a delimited and calcified oval image measuring $0.6 \times 0.6 \mathrm{~cm}$. The tonsillar concretion might have been formed because of a calcification of the lymphoid tissue. On the patient's request, surgical excision was not performed and she will be monitored due to the tendency of such lesions to grow.
\end{abstract}

\section{INTRODUCTION}

Tonsilloliths are calcified structures that develop in enlarged tonsillar crypts that are packed with bacterial and organic debris. ${ }^{1}$ Small tonsillar concretions may be encountered on routine sectioning of gross specimens of tonsils; however, large tonsillar concretions are relatively uncommon, occurring much less often. ${ }^{2,3}$ They can be single, multiple, unilateral or bilateral. ${ }^{3}$

Tonsillar concretions sometimes produce symptoms, including non-specific chronic halitosis, irritable cough, dysphagia, otalgia and a foreign body-like sensation or foul taste. ${ }^{2}$ Patients with tonsillolithiasis may also be asymptom-

\footnotetext{
${ }^{1,2}$ Residents, Department of Oral Diagnosis, Piracicaba Dental School/University of Campinas, São Paulo, Brazil: 3-6*Professors, Department of Oral Diagnosis, Piracicaba Dental School/University of Campinas, São Paulo, Brazil

${ }^{*}$ Correspondence to: Professor Francisco Haiter-Neto Email: haiter@fop.unicamp.br
}

\section{Refereed Paper}

Accepted 9 June 2006

DOI: $10.1038 /$ bdj.2007.175

${ }^{\circledR}$ British Dental Journal 2007; 202: 265-267 atic, with their lesions discovered incidentally on panoramic radiographs or on another cranio radiograph view. ${ }^{4}$ Bacterial and epithelial debris accumulating within tonsillar crypts contributes to the formation of retention cysts and subsequent deposition of inorganic salts. ${ }^{2}$

This report presents a case of a tonsillolithiasis of the right palatine tonsil in a patient who had a history of a tonsillectomy many years ago and presented pharyngeal discomfort with a foreign body sensation and halitosis after the surgery.

\section{CASE REPORT}

A general dental practitioner referred a 47-year-old woman to the Oral Radiological Clinic, Piracicaba Dental School, University of Campinas, for a routine panoramic radiograph. The panoramic film revealed the presence of one radiopaque image located in the right ramus of the mandible (Fig. 1).

Based on the radiographic image, questioning the patient revealed an approximately two-year history of slight dysphagia, halitosis and swallowing pain with a foreign body sensation. Her medical history revealed a tonsillectomy when she was eight years old and the removal of the uvula because of sleep apnoea six years ago. Clinical examination showed no signs of submucosal mass protruding from the soft palate at the right anterior tonsillar pillar level. There were no palpable adenopathies.

To determine the exact location of the lesion, a helicoidal computed tomography (CT) scan of the head was performed (2 $\mathrm{mm}$ of slice thickness with $2 \mathrm{~mm}$ of reconstruction interval), which revealed the presence of a calcified oval mass measuring approximately 0.6 x $0.6 \mathrm{~cm}$ (Figs 2 and 3). The medical history combined with the radiological findings led us to a diagnosis of tonsillolith.

Given the history of a tonsillolith in a patient who had undergone a tonsillectomy, we referred the woman to an otorhinolaryngologist. The doctor confirmed the diagnosis and explained that the presence of the radiopaque area was related to the fact that the tonsils had 


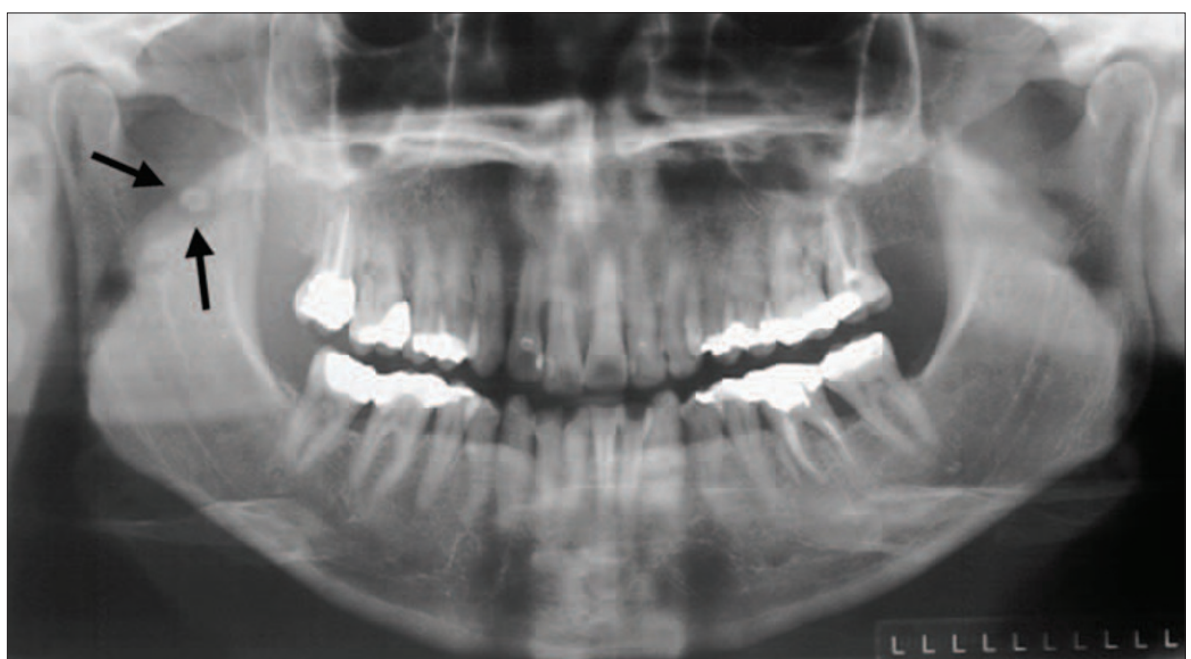

Fig. 1 The arrows point to the tonsillolith located in the right ramus of the mandible

only been partially removed during surgery, making possible the development of the tonsillar concretion.

At the request of the patient, no surgical intervention was carried out for the right tonsillolith.

\section{DISCUSSION}

Tonsilloliths are concretions of varying size and consistency which can occur within the substance of the tonsil or from around it. The size of the tonsillolith can vary and giant tonsilloliths have been reported in the literature. ${ }^{5}$ Large tonsilloliths are relatively uncommon. ${ }^{2-5}$ Histologically, a tonsil consists of a mass of lymphoid tissues that contain follicles with germinal centres. The surface of the tonsil forms crypts lined by stratified squamous epithelium which is less mature than those of the oral mucous membrane. Occasional foci of ciliated epithelium are not uncommon. ${ }^{6}$

The exact aetiology and pathogenesis of the tonsillolith is unknown; ${ }^{7}$ many views have been expressed but no conclusion made. ${ }^{5,8}$ The calcifications develop within a mass of desquamated epithelium, serum, food debris and bacterial colonies. ${ }^{1}$ Recurrent tonsillar inflammation may produce fibrosis at the opening of the tonsillar crypts. Bacterial and epithelial debris then accumulate within these crypts and contribute to the formation of retention cysts. Calcification occurs subsequent to the deposition of inorganic salts and enlargement of the concretion takes place gradually. ${ }^{9}$ Tonsilloliths derive their phosphate and carbonate of lime and magnesia from saliva secreted by the major and minor salivary glands. Tonsillolith consistency ranges from soft and friable to hard as a stone $^{2,4,5,10,11}$ and deposits may be single or multiple. ${ }^{11-13}$

In our case tonsillolithiasis occurred where a past medical history revealed partial removal of the tonsil, thereby making the development of a tonsillar concretion possible. It is always important to remember that the medical history becomes very important when there are no obvious predisposing causes to explain the tendency for patients to develop calcifications. ${ }^{9}$

Tonsilloliths occur more frequently in adults than in children. Cooper et al. ${ }^{2}$ reviewed 23 cases of tonsillolith and found the patients had an age range of 20 to 68 years with no gender predilection. Symptoms are usually non-specific such as chronic sore throat, irritable cough, dysphagia or otalgia.,13,14 A foreign body sensation may also exist with a recurrent foul taste. On occasion a large tonsillolith may ulcerate to the supra-tonsillar fossa or beneath, to the anterior pillar.

Patients with tonsilloliths may also be asymptomatic and their lesions discovered incidentally on panoramic radiographs. Giudice et al. ${ }^{9}$ described a tonsillolith accidentally detected in a patient with a lithiasis of the left submandibular gland. On the panoramic radiograph, tonsilloliths appear as multiple, small, ill-defined radiopacities. Superimposition of hard and soft tissue structures on such radiographic images is common in this anatomic region, creating challenges in interpretation. ${ }^{11}$ Often this difficulty may be overcome by use of computerised tomographs. However, a prominent hamulus and

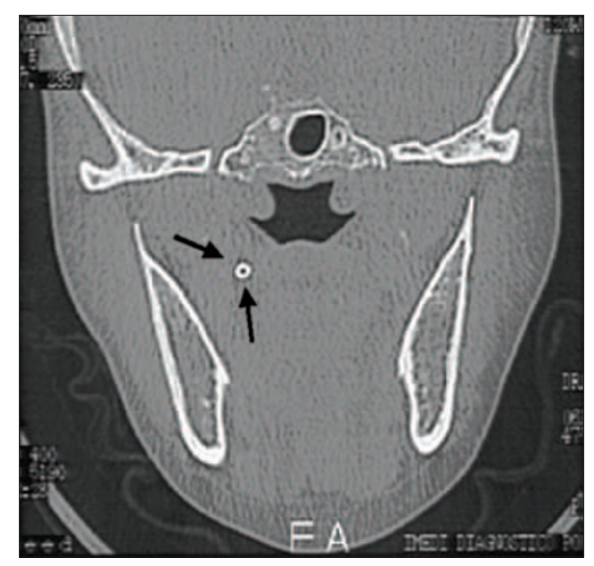

Fig. 2 Coronal CT reconstruction showing the tonsillolith image

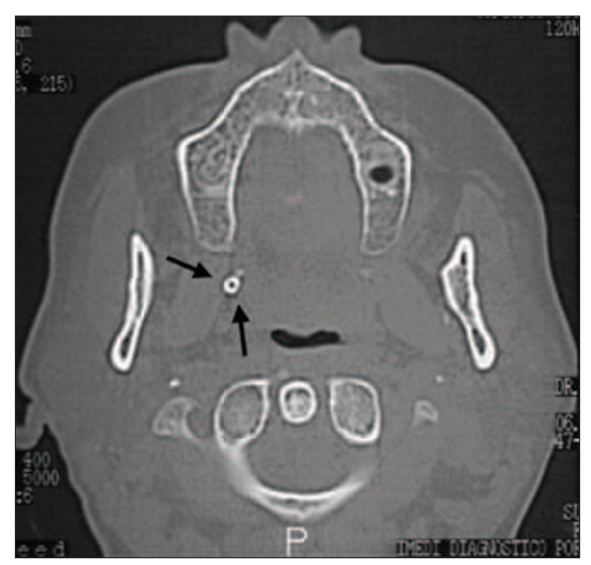

Fig. 3 Axial CT acquisition showing the tonsillolith image

elongated styloid process, calcification of the stylohyoid ligament or unusual prominence of the maxillary tuberosity or mandibular ramus, may simulate tonsillar calculi when only a single CT section is evaluated. Examination of successive scans typically reveals the true nature of these structures. ${ }^{3,5,10,11,13,14}$

On clinical examination, the tonsillolith may appear as a white or yellowish hard object within the tonsillar crypt, thus making the diagnosis fairly obvious. ${ }^{9}$ In our case, the tonsillolith produced few symptoms, such as slight dysphagia and swallowing pain with a foreign body sensation. The bimanual palpation did not detect any local induration in the right peritonsillar region.

Differential diagnosis of tonsillolith includes malignancy, calcified granuloma, diseases such as tertiary syphilis, tuberculosis and deep fungical infection. Foreign bodies, isolated bone, cartilage derived from embryonic rests or an elongated styloid process may also be suspected..$^{9,15}$

Treatment usually involves removal of the tonsillolith by curettage; larger 
lesions may require local excision. ${ }^{12,13}$ If there is evidence of chronic tonsillolith, tonsillectomy offers definitive therapy. In our patient, surgical excision was not performed because she did not want it. The patient will be monitored because of the tendency of such lesions to grow.

1. Neville B W, Damm D D, Allen C M et al. Oral and maxillofacial pathology. $2^{\text {nd }}$ edn. pp 798. Philadelphia: WB Saunders, 2002.

2. Cooper M M, Steinberg J J, Lastra M et al. Tonsillar calculi: report of a case and review of the literature. Oral Surg Oral Med Oral Pathol 1983;
55: 239-243.

3. Pruet C W, Duplan D A. Tonsil concretions and tonsilloliths. Otolaryngol Clin North Am 1987; 20: 305-309.

4. Marshall W G, Irwin N D. Tonsilloliths. Oral Surg Oral Med Oral Pathol 1981; 51: 113.

5. Hiranandani L H. A giant tonsillolith. J Laryngol Otol 1967; 81: 819-822.

6. Ram S, Siar C H, Ismail S M et al. Pseudo bilateral tonsilloliths: a case report and review of the literature. Oral Surg Oral Med Oral Pathol Oral Radio Endod 2004; 98: 110-114.

7. Hadi U M, Samara M S. Giant tonsillolith. Ear Nose Throat J 1985; 64: 507-508.

8. Donat FJ S, Mocholi A P, Ferriol E E etal. Giant tonsillolith: report of a case. Med Oral Patol Oral Cir Bucal 2005; 10: 239-242.
9. Giudice M, Cristofaro M G, Fava M G et al. An unusual tonsillolithiasis in a patient with chronic obstructive sialoadenitis. Dentomaxillofac Radiol 2005; 34: 247-250.

10. Westmore B, Hupp J. Tonsillolith. Oral Surg Oral Med Oral Pathol 2001; 65: 783.

11. Sezer B, Tugsel Z, Bilgen C. An unusual tonsillolith Oral Surg Oral Med Oral Pathol Oral Radiol Endod 2003; 95: 471-473.

12. Jones J W. A tonsillolith. Br Dent J 1996; 180: 128

13. Neshat K, Penna K J, Shah D H. Tonsillolith: a case report. J Oral Maxillofac Surg 2001; 59: 692-693

14. Gadgil R M. An unusually large tonsillolith. Oral Surg Oral Med Oral Pathol 1984; 58: 237.

15. Aspestrand F, Kolbenstvedt A. Calcifications of the palatine tonsillary region: CT demonstration. Radiology 1987; 165: 479-480.

\section{AUTHOR NOTICE}

The acceptability of dually-qualified dental hygienist-therapists to general dental practitioners in South-East Scotland (Br Dent J 2007; 202: E8; featured in the CPD section of BDJ 202 issue 3)

At the time this paper was accepted for publication, all information included in the text and CPD section was entirely accurate. However, during the time between acceptance and publication of the article, the situation regarding the necessity for a dentist to be on the premises while inferior dental block is being administered by non-dentist clinicians was removed. Consequently, none of the four possible answers given in Article 2 Question 4 of the CPD for this issue were correct. Option B was, however, correct in the context of the published paper.

M. K. Ross 